\title{
PCSK9 inhibition: the way forward in the treatment of dyslipidemia
}

\author{
Robert M. Stoekenbroek, John JP Kastelein ${ }^{*}$ and Roeland Huijgen
}

\begin{abstract}
Barely a decade after the discovery of the gene encoding proprotein convertase subtilisin/kexin type 9 (PCSK9) and its recognition as a key player in cholesterol metabolism, PCSK9 inhibition is now considered an exciting approach in the reduction of residual risk of cardiovascular disease. The progress from PCSK9 discovery to the development of targeted treatment has been unprecedented in terms of scale and speed. The first suggestion of a link between PCSK9 and hypercholesterolemia was published in 2003; a decade later, two meta-analyses of clinical trials comparing anti-PCSK9 treatment to placebo or ezetimibe, including >10,000 hypercholesterolemic individuals, were published. Currently, three PCSK9 inhibitors are being evaluated in clinical outcome trials and the results will determine the future of these lipid-lowering therapies by establishing their clinical efficacy in terms of cardiovascular event reduction, safety, and the consequences of prolonged exposure to very low levels of LDL-cholesterol. Irrespective of their outcomes, the exceptionally rapid development of these drugs exemplifies how novel technologies, genetic validation, and rapid clinical progression provide the tools to expedite the development of new drugs.
\end{abstract}

Keywords: Cholesterol-lowering drugs, LDL-cholesterol, PCSK9

\section{Background}

Two decades after the results of the Scandinavian Simvastatin Survival Study first showed that statins effectively improve survival in patients with cardiovascular disease (CVD), thus initiating a revolution in the treatment of dyslipidemia [1], ezetimibe has been the only drug shown to further improve outcomes for dyslipidemic patients [2]. Research programs of novel compounds were prematurely halted due to safety concerns or a lack of efficacy and the use of such drugs was often associated with only modest reductions in low-density lipoprotein cholesterol (LDL-C) [3-6]. Established lipidmodifying compounds, such as fibrates and nicotinic acids, failed to improve CVD events as the primary outcome when used in conjunction with optimal statin therapy $[7,8]$. Therefore, recent guidelines no longer recommend the routine use of non-statin drugs in conjunction with high-intensity statin treatment [9]. Nevertheless, many patients fail to achieve acceptable lipid control with or are unable to tolerate statin treatment $[10,11]$. Additionally, consideration of the potential

\footnotetext{
* Correspondence: j.j.kastelein@amc.uva.nl

Department of Vascular Medicine, Academic Medical Center, University of Amsterdam, PO Box 22660, Meibergdreef 9, 1105 AZ Amsterdam, Netherlands
}

merits of further LDL-C reductions resurfaced when the results of the IMProved Reduction of Outcomes: Vytorin Efficacy International Trial (IMPROVE-IT) study indicated that addition of ezetimibe to simvastatin significantly reduced the risk of subsequent CVD events in patients with acute coronary syndromes [2]. Given these considerations and since the discovery of the association between mutations in proprotein convertase subtilisin/ kexin type 9 (PCSK9) and familial hypercholesterolemia (FH) in 2003 [12], PCSK9 inhibitors have emerged as the prime candidate to further improve outcomes for CVD patients and may initiate the next revolution in anti-atherosclerotic therapy.

\section{Discovery and function}

PCSK9 was recognized to play an important role in LDL-C metabolism after the identification of gain-offunction mutations in two French families with $\mathrm{FH}$ without mutations in other $\mathrm{FH}$-associated genes [12]. Subsequent experiments revealed that PCSK9 increases levels of LDL-C by reducing the available pool of hepatic LDL-receptors [13]. In the absence of PCSK9, the LDLreceptor is recycled back to the plasma membrane. Binding of PCSK9, on the other hand, prevents LDL-receptor 
recycling and instead targets it for lysosomal degradation (Fig. 1a) [13]. An extensive review of the underlying mechanisms of PCSK9 inhibition was recently provided by Lambert et al. [13]. Large cohort studies have revealed associations between variations in the PCSK9 gene and LDL-C levels and CVD risk [14]. In addition, studies have shown that statin treatment increases PCSK9 levels [13]. The inverse relation between PCSK9 activity levels and LDL-receptors suggests that PCSK9 inhibition could have a synergistic effect with statins on LDL-C. Therefore, PCSK9 has been identified as a promising target for antiatherosclerotic drug development. Several strategies have been developed to reduce PCSK9 function, including binding of plasma PCSK9 by monoclonal antibodies, reducing PCSK9 expression by silencing RNA, or vaccination against PCSK9 $[15,16]$. The present review focuses primarily on PCSK9-inhibiting antibodies due to their presently more advanced clinical development.

\section{Development of PCSK9-inhibiting antibodies}

The first reports of phase I studies of three PCSK9inhibiting antibodies, the mechanism of action of which is shown in Fig. 1b, were published a mere decade after the discovery of PCSK9. In their landmark study, Stein et al. [17] demonstrated the ability of the PCSK9inhibiting antibody alirocumab to reduce LDL-C by more than $60 \%$ in both healthy volunteers and patients with FH. Subsequent phase I studies of other PCSK9

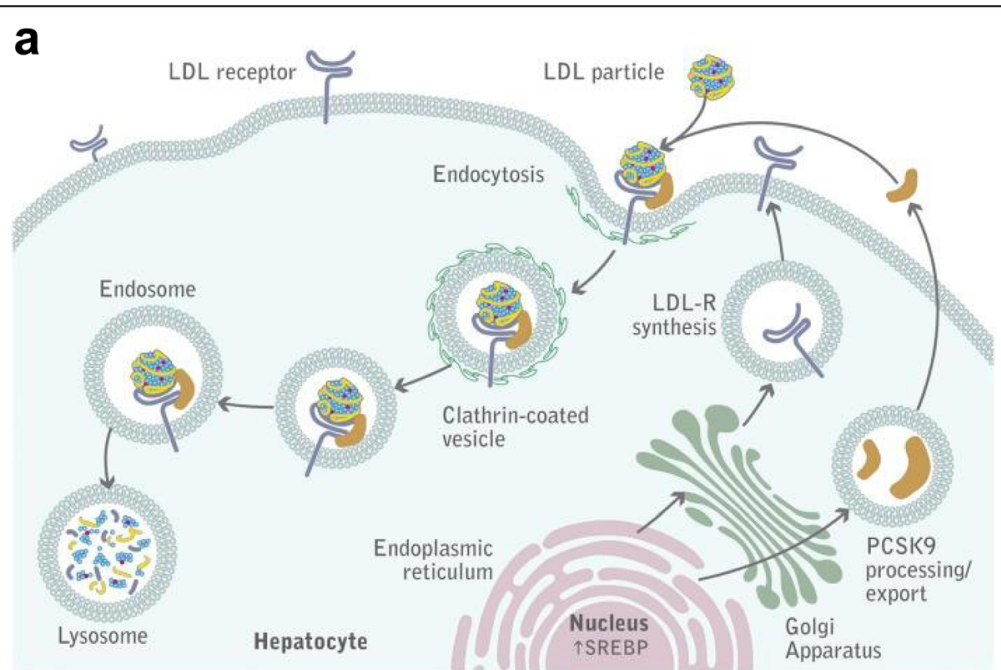

b

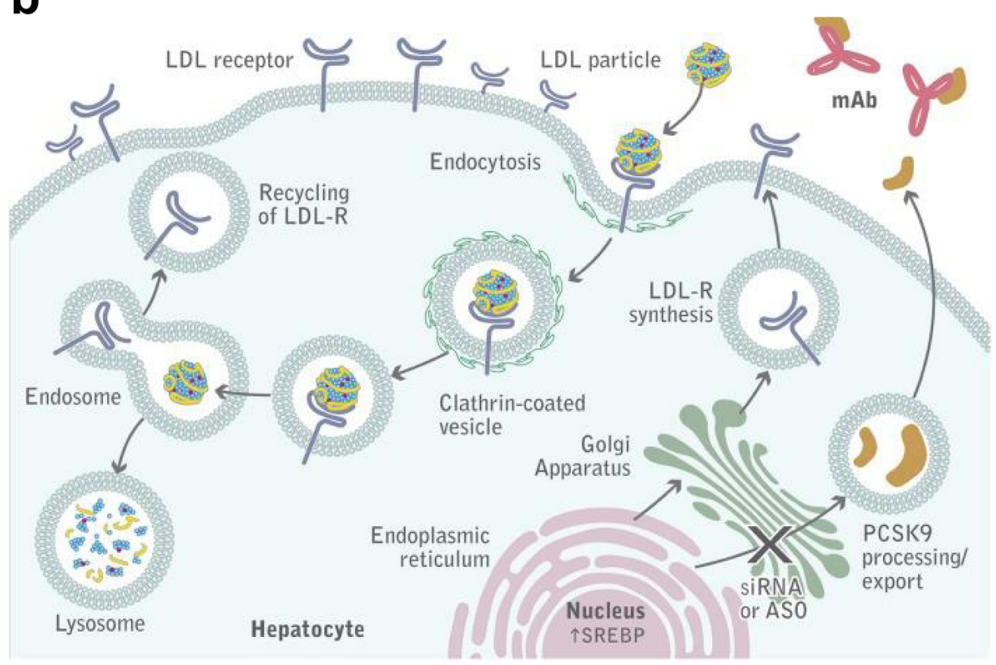

Fig. 1 a. PCSK9-mediated degradation of low-density lipoprotein receptor (LDLR). A complex of low-density lipoprotein cholesterol (LDL-C), LDLR, and PCSK9 is internalized into hepatocytes within clathrin-coated pits and subsequently undergoes lysosomal degradation. b. PCSK9 inhibition. Monoclonal antibodies bound to PCSK9 prevent the association between PCSK9 and LDLR. LDLR binds and internalizes LDL-C particles, which are then degraded in the lysosome, whereas the LDLR is recycled back to the plasma membrane. Re-use kindly permitted by the American Society for Biochemistry and Molecular Biology, Inc. Figure derived from The PCSK9 decade [13] 
inhibitors, including evolocumab and bococizumab, confirmed these findings [18]. Hitherto, the clinical potential of PCSK9 inhibition with monoclonal antibodies has been studied in more than 20 short-term clinical trials against various background lipid-lowering therapies and with both placebo and ezetimibe as a comparator treatment. The populations reflected the major categories of patients for whom PCSK9 inhibition will likely be used in practice: familial- and non-familial hypercholesterolemia, statin-intolerant patients, and high-risk secondary prevention patients who fail to achieve acceptable lipid goals with currently available treatment options.

\section{Effect of PCSK9-inhibiting antibodies}

Two recent meta-analyses evaluated the clinical potential of antibody PCSK9 inhibition in $>10,000$ patients who participated in over 20 phase II and III trials [19, 20]. These meta-analyses included data from most of the available studies with alirocumab and evolocumab. Not included in the first meta-analysis were observations from the Open-Label Study of Long-Term Evaluation against LDL Cholesterol (OSLER), which was an open label extension study of participants who had completed phase II or III studies ("parent trials") of evolocumab [21]. The results were, in essence, similar to those from the large dataset in the meta-analyses [19]. In contrast to the substantial body of evidence on alirocumab and evolocumab, longer-term safety and efficacy data on bococizumab is relatively limited, with only one full publication on 351 patients available to date [22].

\section{Effects on lipids}

All trials confirmed the beneficial effect of PCSK9 inhibition with evolocumab and alirocumab on LDL-C levels. The use of PCSK9 monoclonal antibodies was associated with mean LDL-C reductions of approximately $50 \%$ $[19,20]$. These results persisted during follow-up, and were similar across different doses, patient populations, and in patients with or without background statin therapy [19-21]. Compared to ezetimibe, PCSK9 inhibition resulted in a mean LDL-C reduction of approximately $36 \%$ (95\% confidence interval (CI), 33$39 \%$ [19]. In addition to their LDL-C lowering effect, PCSK9 inhibitors consistently increased high-density lipoprotein cholesterol by approximately $6 \%(95 \%$ CI, 6$7 \%$ ) and lowered lipoprotein(a) by approximately $26 \%$ (95 \% CI, 23-30 \%) both in placebo- and ezetimibecontrolled trials [19]. The effects on lipid levels were similar in trials on evolocumab, alirocumab, and bococizumab $[19,20,22]$.

\section{Clinical efficacy}

The published individual trials were not powered to study the efficacy in terms of clinical outcomes. In total,
10 randomized controlled trials, with over 5000 participants, reported data on myocardial infarction [19]. One of the meta-analyses studied myocardial infarction rates and showed a significantly lower rate $(0.6 \% ; 19 / 3289$ patients) in PCSK9 inhibitor-treated patients compared to those who received no anti-PCSK9 treatment (1.0\%; 19/1906 patients; odds ratio, 0.49; $95 \%$ CI, $0.26-$ 0.93) [19]. Similarly, statistically significant reductions in CVD event rates were reported during the 1-year follow-up of the OSLER and ODYSSEY long-term trials [21, 23]. Furthermore, these preliminary analyses suggest a statistically significant reduction in all-cause mortality and a non-significant reduction in CVD mortality. Because of the limited number of events, long-term clinical outcome studies should be awaited to substantiate these findings.

\section{Safety}

Pooled analysis of serious adverse event rates from phase II and III studies demonstrated similar incidence rates in patients treated with PCSK9 inhibitors versus controls [19]. Similarly, there were no differences in the incidence of any adverse events compared to placebo, irrespective of the dosage of evolocumab [20]. Moreover, adherence rates were similar in both groups. Given that PCSK9 inhibitors could be a valuable option for statin-intolerant patients, the observation that elevated creatine kinase occurred less frequently in PCSK9 inhibitor-treated patients than in controls is of interest $[19,20]$. None of the phase III trials reported the presence of neutralizing antibodies. The favorable safety profile of PCSK9 inhibitors [24], as well as the results of several meta-analyses of statin trials [25], provide reassuring evidence on the short-term safety of achieving very low levels of LDL-C. The observation of a slightly increased occurrence of neurocognitive dysfunction in patients receiving alirocumab or evolocumab in the ODYSSEY long-term trial (1.2 \% vs. $0.5 \% ; P=0.17)$ [21] and OSLER trial $(0.9 \%$ vs. $0.2 \% ; P=0.3$ ) [23] has led to the initiation of a study designed specifically to evaluate neurocognitive effects of PCSK9 inhibition with evolocumab in 4000 individuals (NCT Trial Identifier: NCT02207634). Further, inherent to monoclonal antibodies is their subcutaneous administration. A prevalence of approximately $5 \%$ of injection site reactions was reported by patients in the active treatment arms with evolocumab or alirocumab $[21,23]$.

\section{Future perspectives}

The results of large ongoing clinical outcome trials of PCSK9 inhibitors will determine the way forward in the treatment of dyslipidemia since these trials will indicate whether additional LDL-C lowering safely translates into cardiovascular benefit. Although it would be premature 
to endorse these drugs for widespread use before the results of ongoing trials are available, it is interesting to speculate on the categories of patients for whom PCSK9 inhibition would be first applied. Notably, the United States Food and Drug Administration has recently approved alirocumab, in addition to diet and maximally tolerated statins, in patients with heterozygous $\mathrm{FH}$ or clinical CVD who require additional LDL-C lowering [26]. Similarly, the European Medicines Agency has recommended approval of alirocumab and evolocumab for patients who fail to achieve acceptable lipid control despite optimal statin therapy, but also explicitly mentions patients with homozygous $\mathrm{FH}$ and statin-intolerant patients [27, 28]. Arguably, the largest group of patients who will potentially benefit from PCSK9 inhibition consists of those remaining at increased risk of CVD despite currently available lipid-lowering treatment due to, for example, having a very high baseline CVD risk. Statin treatment will likely remain the basis of lipid lowering treatment in the foreseeable future due to their relatively low costs, oral availability, and their established beneficial safety profile and clinical efficacy. However, results of the IMPROVE-IT study confirmed the 'lower is better' paradigm regarding LDL-C levels and CVD risk, demonstrating additional clinical benefit through the addition of ezetimibe to simvastatin [2]. Importantly, the risk reduction associated with additional LDL-C lowering appears to be independent of baseline LDL-C [2, 24]. Discussion on the potential role of PCSK9 inhibitors in the treatment of this large and heterogeneous group of patients will therefore focus on the desired balance between additional absolute risk reduction and costs. In the IMPROVE-IT trial, addition of ezetimibe to simvastatin resulted in an absolute risk reduction of $2 \%$ in
CVD events after 7 years of treatment, or a number needed to treat for 5 years of approximately 70 to prevent one CVD event [2]. The number needed to treat for the more potent PCSK9 inhibitors will likely be three-fold lower [21, 23].

Another group of patients who may benefit from PCSK9 inhibitors could be those with a strict indication for lipid lowering but who are statin intolerant. Indeed, this category of patients is included in the recent European Medicines Agency recommendation [27]. Although multiple definitions of statin intolerance exist, the magnitude of the problem is illustrated by the observation that $75 \%$ of patients discontinue statins within 2 years, with statin-associated muscle symptoms being the prevailing reason in approximately $60 \%$ of cases $[10,29]$. Evolocumab and alirocumab showed a good safety and tolerability profile in statin-intolerant patients [30-32]; bococizumab is being tested in statinintolerant patients (NCT Trial Identifier: NCT02135029). The potential of PCSK9 inhibitors as an alternative for statin-intolerant patients who fail to achieve acceptable LDL-C control on currently available therapies has been recognized in the current European Atherosclerosis Society guideline [33].

Furthermore, PCSK9 inhibition may be of benefit in the treatment of patients with homozygous $\mathrm{FH}$. Currently available oral lipid-lowering agents do lower LDL-C in most homozygous FH patients, but the limited efficacy means that these patients are currently often dependent on invasive treatment modalities such as LDL-C apheresis or Apolipoprotein B or microsomal triglyceride transfer protein inhibition, with the latter two having been associated with steatosis [34-37]. Evolocumab has been proven efficacious in reducing LDL-C in a

Table 1 Ongoing clinical outcome trials of PCSK9 inhibitors

\begin{tabular}{|c|c|c|c|c|}
\hline Trial name & Study drug & Patient population & Primary outcome measure & Follow-up \\
\hline FOURIERNCT01764633 & Evolocumab & $\begin{array}{l}n=27,000 \text {; history of CVD - at } \\
\text { high risk of recurrent event; } \\
\mathrm{LDL}-\mathrm{C} \geq 70 \mathrm{mg} / \mathrm{dL} \text { or non-HDL-C } \\
\geq 100 \mathrm{mg} / \mathrm{dL} \text {; background statin } \\
\text { therapy }\end{array}$ & $\begin{array}{l}\text { Time to cardiovascular death, myocardial } \\
\text { infarction, hospitalization for unstable } \\
\text { angina, stroke, or coronary revascularization }\end{array}$ & 5 years \\
\hline ODYSSEY OUTCOMESNCT01663402 & Alirocumab & $\begin{array}{l}n=18,000 \text {; acute coronary syndrome } \\
<52 \text { weeks earlier; } L D L-C \geq 70 \mathrm{mg} / \mathrm{dL} \\
\text { or non-HDL-C } \geq 100 \mathrm{mg} / \mathrm{dL} ; \\
\text { background statin therapy }\end{array}$ & $\begin{array}{l}\text { Time to cardiovascular death, non-fatal } \\
\text { myocardial infarction, hospitalization for } \\
\text { unstable angina, or stroke }\end{array}$ & 64 months \\
\hline SPIRE-1NCT01975376 & Bococizumab & $\begin{array}{l}n=17,000 \text {; high risk of CVD event, } \\
\text { primary and secondary prevention; } \\
\text { background lipid-lowering treatment; } \\
\text { LDL-C } 70-100 \mathrm{mg} / \mathrm{dL} \text { or non-HDL-C } \\
100-130 \mathrm{mg} / \mathrm{dL}\end{array}$ & $\begin{array}{l}\text { Time to composite major cardiovascular } \\
\text { event (cardiovascular death, non-fatal } \\
\text { myocardial infarction, non-fatal stroke, } \\
\text { and hospitalization for unstable angina) }\end{array}$ & 60 months \\
\hline SPIRE-2NCT01975389 & Bococizumab & $\begin{array}{l}n=9000 \text {; high risk of CVD event; } \\
\text { background lipid-lowering treatment; } \\
\mathrm{LDL}-\mathrm{C} \geq 100 \mathrm{mg} / \mathrm{dL} \text { or non-HDL-C } \\
\geq 130 \mathrm{mg} / \mathrm{dL}\end{array}$ & $\begin{array}{l}\text { Time to composite major cardiovascular } \\
\text { event (cardiovascular death, non-fatal } \\
\text { myocardial infarction, non-fatal stroke, } \\
\text { and hospitalization for unstable angina) }\end{array}$ & 60 months \\
\hline
\end{tabular}


12-week proof of concept, randomized controlled trial during including 50 homozygous FH patients, but only in those carrying alleles of the LDL-receptor with some residual activity, as can be expected from the mechanism of action of PCSK9 inhibition (Fig. 1) [38]. Similarly, despite the potency of statins, only a minority of patients with heterozygous FH attain optimal cholesterol levels and considerable excess mortality still exists [11, 39]. Published trials of PCSK9 inhibitors have already demonstrated the potential to reach unprecedented low LDL-C levels in heterozygous FH and currently ongoing clinical outcome studies will establish whether addition of PCSK9 inhibition to current treatment confers sustained clinical benefit in this patient population (NCT Trial Identifier: NCT01968980) [40-42].

All of the four ongoing clinical outcome trials on PCSK9-inhibition antibodies include high-risk patients (either clinically manifest CVD or dyslipidemia) and will determine the efficacy of PCSK9 inhibitors added to lipid-lowering therapy in reducing major CVD event rates compared to placebo over approximately 5 years of follow-up (Table 1). The first results of these trials are expected in 2018. Ultimately, the societal benefit of these treatments will depend on their costs, safety, and efficacy. The expected high cost of PCSK9 inhibitors could indicate that their use may only be cost-effective in the treatment of patients with a particularly high baseline risk; a crucial challenge will be defining the level of baseline risk at which PCSK9 inhibition is valuable. The benefit of PCSK9 inhibition in practice will further depend on therapy compliance and therefore dose and frequency of administration need to be carefully considered. Finally, despite the fact that ongoing phase III trials will determine the safety of PCSK9 inhibition after 5 years of follow-up, post-marketing registration and extended follow-up studies are required to confirm their safety in the longer term.

\section{Conclusions}

Merely a decade after the discovery of the essential role of PCSK9 in LDL-C metabolism, its inhibition has emerged as one of the most promising novel strategies to reduce CVD. Their remarkable efficacy in reducing LDL-C and the possible synergistic effects with statins, combined with a favorable safety profile and tolerability, provide these drugs with the potential to revolutionize the treatment of patients at high risk of CVD. Ongoing clinical outcome trials will provide a definite answer to the question on the clinical benefit of further reducing LDL-C. Irrespective of their results, the rapid development of these drugs illustrates the possibilities offered by new technologies and genetic research methods.

\section{Abbreviations}

Cl: Confidence interval; CVD: Cardiovascular disease; FH: Familial

hypercholesterolemia; IMPROVE-IT: IMProved Reduction of Outcomes: Vytorin
Efficacy International trial; LDL-C: Low-density lipoprotein cholesterol; OSLER: Open-Label Study of Long-Term Evaluation against LDL Cholesterol; PCSK9: Proprotein convertase subtilisin/kexin type 9.

\section{Competing interests}

Prof. Kastelein has received consulting fees from Cerenis Therapeutics, The Medicines Company, CSL Behring, Amgen, Regeneron Pharmaceuticals, Eli Lilly, Genzyme, Aegerion Pharmaceuticals, Esperion Therapeutics, AstraZeneca, Omthera Pharmaceuticals, ProNova, Vascular Biogenics, Boehringer Ingelheim, Catabasis Pharmaceuticals, AtheroNova, uniQure, Novartis, Merck, Pfizer, Isis Pharmaceuticals, Kowa, and Dezima Pharma. The remaining authors report no potential competing interests.

\section{Authors' contributions}

$\mathrm{RS}$ and $\mathrm{RH}$ drafted the manuscript and JK critically revised the manuscript for important intellectual content. All authors made substantial contributions to the design of the manuscript and read and approved the final manuscript.

Received: 9 July 2015 Accepted: 22 September 2015

Published online: 12 October 2015

\section{References}

1. Randomised trial of cholesterol lowering in 4444 patients with coronary heart disease: the Scandinavian Simvastatin Survival Study (4S). Lancet. 1994:344:1383-9.

2. Cannon CP, Blazing MA, Giugliano RP, McCagg A, White JA, Theroux P, et al. IMPROVE-IT Investigators. Ezetimibe added to statin therapy after acute coronary syndromes. N Engl J Med. 2015;372:2387-97.

3. Barter PJ, Caulfield M, Eriksson M, Grundy SM, Kastelein JJ, Komajda M, et al. ILLUMINATE Investigators. Effects of torcetrapib in patients at high risk for coronary events. N Engl J Med. 2007;357:2109-22.

4. Investigators AIM-HIGH, Boden WE, Probstfield JL, Anderson T, Chaitman BR, Desvignes-Nickens $P$, et al. Niacin in patients with low HDL cholesterol levels receiving intensive statin therapy. N Engl J Med. 2011;365:2255-67.

5. HPS2-THRIVE Collaborative Group, Landray MJ, Haynes R, Hopewell JC, Parish S, Aung T, et al. Effects of extended-release niacin with laropiprant in high-risk patients. N Engl J Med. 2014;371:203-12.

6. Schwartz GG, Olsson AG, Abt M, Ballantyne CM, Barter PJ, Brumm J, et al. dal-OUTCOMES Investigators. Effects of dalcetrapib in patients with a recent acute coronary syndrome. N Engl J Med. 2012;367:2089-99.

7. ACCORD Study Group, Ginsberg HN, Elam MB, Lovato LC, Crouse 3rd JR, Leiter LA, et al. Effects of combination lipid therapy in type 2 diabetes mellitus. N Engl J Med. 2010;362:1563-74.

8. Keech A, Simes RJ, Barter P, Best J, Scott R, Taskinen MR, et al. FIELD study investigators. Effects of long-term fenofibrate therapy on cardiovascular events in 9795 people with type 2 diabetes mellitus (the FIELD study): randomised controlled trial. Lancet. 2005;366:1849-61.

9. Stone NJ, Robinson JG, Lichtenstein AH, Bairey Merz CN, Blum CB, Eckel RH, et al. American College of Cardiology/American Heart Association Task Force on Practice Guidelines. 2013 ACC/AHA guideline on the treatment of blood cholesterol to reduce atherosclerotic cardiovascular risk in adults: a report of the American College of Cardiology/American Heart Association Task Force on Practice Guidelines. J Am Coll Cardiol. 2014;63:2889-934.

10. Chodick G, Shalev V, Gerber Y, Heymann AD, Silber H, Simah V, et al. Long-term persistence with statin treatment in a not-for-profit health maintenance organization: a population-based retrospective cohort study in Israel. Clin Ther. 2008;30:2167-79.

11. Pijlman $A H$, Huijgen $R$, Verhagen $S N$, Imholz BP, Liem AH, Kastelein JJ, et al. Evaluation of cholesterol lowering treatment of patients with familial hypercholesterolemia: a large cross-sectional study in The Netherlands. Atherosclerosis. 2010;209:189-94.

12. Abifadel M, Varret M, Rabes JP, Allard D, Ouguerram K, Devillers M, et al. Mutations in PCSK9 cause autosomal dominant hypercholesterolemia. Nat Genet. 2003;34:154-6.

13. Lambert G, Sjouke B, Choque B, Kastelein JJ, Hovingh GK. The PCSK9 decade. J Lipid Res. 2012;53:2515-24.

14. Abifadel M, Elbitar S, El Khoury P, Ghaleb Y, Chemaly M, Moussalli ML, et al. Living the PCSK9 adventure: from the identification of a new gene in familial hypercholesterolemia towards a potential new class of anticholesterol drugs. Curr Atheroscler Rep. 2014;16:439. 
15. Fitzgerald K, Frank-Kamenetsky M, Shulga-Morskaya S, Liebow A, Bettencourt BR, Sutherland JE, et al. Effect of an RNA interference drug on the synthesis of proprotein convertase subtilisin/kexin type 9 (PCSK9) and the concentration of serum LDL cholesterol in healthy volunteers: a randomised, single-blind, placebo-controlled, phase 1 trial. Lancet. 2014;383:60-8.

16. Duff CJ, Scott MJ, Kirby IT, Hutchinson SE, Martin SL, Hooper NM. Antibodymediated disruption of the interaction between PCSK9 and the low-density lipoprotein receptor. Biochem J. 2009;419:577-84.

17. Stein EA, Mellis S, Yancopoulos GD, Stahl N, Logan D, Smith WB, et al. Effect of a monoclonal antibody to PCSK9 on LDL cholesterol. N Engl J Med. 2012;366:1108-18.

18. Dadu RT, Ballantyne CM. Lipid lowering with PCSK9 inhibitors. Nat Rev Cardiol. 2014;11:563-75.

19. Navarese EP, Kolodziejczak M, Schulze V, Gurbel PA, Tantry U, Lin Y, et al. Effects of proprotein convertase subtilisin/kexin type 9 antibodies in adults with hypercholesterolemia: a systematic review and meta-analysis. Ann Intern Med. 2015;163:40-51.

20. Zhang XL, Zhu QQ, Zhu L, Chen JZ, Chen QH, Li GN, et al. Safety and efficacy of anti-PCSK9 antibodies: a meta-analysis of 25 randomized, controlled trials. BMC Med. 2015;13:123.

21. Sabatine MS, Giugliano RP, Wiviott SD, Raal FJ, Blom DJ, Robinson J, et al. Open-Label Study of Long-Term Evaluation against LDL Cholesterol (OSLER) Investigators. Efficacy and safety of evolocumab in reducing lipids and cardiovascular events. N Engl J Med. 2015;372:1500-9.

22. Ballantyne CM, Neutel J, Cropp A, Duggan W, Wang EQ, Plowchalk D, et al Results of bococizumab, a monoclonal antibody against proprotein convertase subtilisin/kexin type 9, from a randomized, placebo-controlled, dose-ranging study in statin-treated subjects with hypercholesterolemia. Am J Cardiol. 2015;115:1212-21.

23. Robinson JG, Farnier M, Krempf M, Bergeron J, Luc G, Averna M, et al. Efficacy and safety of alirocumab in reducing lipids and cardiovascular events. N Engl J Med. 2015;372:1489-99.

24. Cholesterol Treatment Trialists' (CTT) Collaboration, Baigent C, Blackwell L, Emberson J, Holland LE, Reith C, et al. Efficacy and safety of more intensive lowering of LDL cholesterol: a meta-analysis of data from 170,000 participants in 26 randomised trials. Lancet. 2010;376:1670-81.

25. Boekholdt SM, Hovingh GK, Mora S, Arsenault BJ, Amarenco P, Pedersen TR, et al. Very low levels of atherogenic lipoproteins and the risk for cardiovascular events: a meta-analysis of statin trials. J Am College Cardiol. 2014;64:485-94.

26. US Food and Drug Administration. FDA News Release. FDA approves Praluent to treat certain patients with high cholesterol. First in a new class of injectable cholesterol-lowering drugs. http://www.fda.gov/NewsEvents/ Newsroom/PressAnnouncements/ucm455883.htm. Last accessed 30-09-2015.

27. European Medicines Agency. Praluent recommended for approval to lower cholesterol. Medicine to offer therapy for patients unable to control high cholesterol with currently available treatment http:// www.ema.europa.eu/ema/index.jsp?curl=pages/news_and_events/news/ 2015/07/news_detail_002377.jsp\&mid=WC0b01ac058004d5c1. Last accessed 30-09-2015.

28. European Medicines Agency. First-in-class treatment to lower cholesterol. Repatha to offer therapy for patients unable to control high cholesterol with currently available treatment. http://www.ema.europa.eu/ema/ index.jsp?curl=pages/news_and_events/news/2015/05/news_detail_ 002336.jsp\&mid=WC0b01ac058004d5c1. Last accessed 30-09-2015.

29. Cohen JD, Brinton EA, Ito MK, Jacobson TA. Understanding Statin Use in America and Gaps in Patient Education (USAGE): an internet-based survey of 10,138 current and former statin users. J Clin Lipidol. 2012;6:208-15.

30. Stroes E, Colquhoun D, Sullivan D, Civeira F, Rosenson RS, Watts GF, et al. Anti-PCSK9 antibody effectively lowers cholesterol in patients with statin intolerance: the GAUSS-2 randomized, placebo-controlled phase 3 clinical trial of evolocumab. J Am Coll Cardiol. 2014;63:2541-8.

31. Sullivan D, Olsson AG, Scott R, Kim JB, Xue A, Gebski V, et al. Effect of a monoclonal antibody to PCSK9 on low-density lipoprotein cholesterol levels in statin-intolerant patients: the GAUSS randomized trial. JAMA. 2012;308:2497-506.

32. ODYSSEY ALTERNATIVE: Efficacy and safety of alirocumab versus ezetimibe, in patients with statin intolerance as defined by a placebo run-in and statin rechallenge arm. https://my.americanheart.org/idc/groups/ahamah-public/ @wcm/@sop/@scon/documents/downloadable/ucm_469684.pdf. Accessed 30 September 2015.

33. Stroes ES, Thompson PD, Corsini A, Vladutiu GD, Raal FJ, Ray KK, et al. Statin-associated muscle symptoms: impact on statin therapy-European Atherosclerosis Society Consensus Panel Statement on Assessment, Aetiology and Management. Eur Heart J. 2015;36:1012-22.

34. Cuchel M, Bruckert E, Ginsberg HN, Raal FJ, Santos RD, Hegele RA, et al. Homozygous familial hypercholesterolaemia: new insights and guidance for clinicians to improve detection and clinical management. A position paper from the Consensus Panel on Familial Hypercholesterolaemia of the European Atherosclerosis Society. Eur Heart J. 2014;35:2146-57.

35. Cuchel M, Meagher EA, du Toit TH, Blom DJ, Marais AD, Hegele RA, et al. Phase $3 \mathrm{HoFH}$ Lomitapide Study investigators. Efficacy and safety of a microsomal triglyceride transfer protein inhibitor in patients with homozygous familial hypercholesterolaemia: a single-arm, open-label, phase 3 study. Lancet. 2013;381:40-6.

36. Raal FJ, Santos RD, Blom DJ, Marais AD, Charng MJ, Cromwell WC, et al. Mipomersen, an apolipoprotein B synthesis inhibitor, for lowering of LDL cholesterol concentrations in patients with homozygous familial hypercholesterolaemia: a randomised, double-blind, placebo-controlled trial. Lancet. 2010;375:998-1006.

37. Stefanutti C, Blom DJ, Averna MR, Meagher EA, Theron HD, Marais AD, et al. The lipid-lowering effects of lomitapide are unaffected by adjunctive apheresis in patients with homozygous familial hypercholesterolaemia-A post-hoc analysis of a Phase 3, single-arm, open-label trial. Atherosclerosis. 2015;240:408-14.

38. Raal FJ, Honarpour N, Blom DJ, Hovingh GK, Xu F, Scott R, et al. TESLA Investigators. Inhibition of PCSK9 with evolocumab in homozygous familial hypercholesterolaemia (TESLA Part B): a randomised, double-blind, placebocontrolled trial. Lancet. 2015;385:341-50.

39. Mundal L, Sarancic M, Ose L, Iversen PO, Borgan JK, Veierod MB, et al. Mortality among patients with familial hypercholesterolemia: a registrybased study in Norway, 1992-2010. J Am Heart Assoc. 2014;3:e001236.

40. Raal FJ, Stein EA, Dufour R, Turner T, Civeira F, Burgess $L$, et al. RUTHERFORD-2 Investigators. PCSK9 inhibition with evolocumab (AMG 145) in heterozygous familial hypercholesterolaemia (RUTHERFORD-2): a randomised, double-blind, placebo-controlled trial. Lancet. 2015;385:331-40.

41. Kastelein JJ, Robinson JG, Farnier M, Krempf M, Langslet G, Lorenzato C, et al. Efficacy and safety of alirocumab in patients with heterozygous familial hypercholesterolemia not adequately controlled with current lipid-lowering therapy: design and rationale of the ODYSSEY FH studies. Cardiovasc Drugs Ther. 2014;28:281-9.

42. Ginsberg HN. ODYSSEY HIGH FH: efficacy and safety of alirocumab in patients with severe heterozygous familial hypercholesterolemia. Chicago, IL: AHA; 2014. http://my.americanheart.org/idc/groups/ahamahpublic/@wcm/@sop/ @scon/documents/downloadable/ucm_469616.pdf. Accessed 30 September 2015.

\section{Submit your next manuscript to BioMed Central and take full advantage of:}

- Convenient online submission

- Thorough peer review

- No space constraints or color figure charges

- Immediate publication on acceptance

- Inclusion in PubMed, CAS, Scopus and Google Scholar

- Research which is freely available for redistribution 